\title{
Primary giant cell-rich lesions of bone with role of denosumab - histopathological study with clinico- radiological correlation
}

\begin{abstract}
Introduction: The diagnosis of primary giant cell-rich lesion of bone is often difficult even for experienced pathologist. The diagnostic histological features are: multinucleated osteoclast-like giant cell and a mononuclear stroma. But sometimes, from the histological picture alone, it is difficult to differentiate between different lesions such as a Giant-cell tumour of bone, Aneurysmal Bone Cyst and Giant-cell Reparative Granuloma. Many of these lesions show some characteristic features such as typical anatomic location and age of the patient, which are also important supporting factor for diagnosis. Hence histopathological study with clinico-radiological correlation is mandatory for precise and accurate diagnosis. These parameters are important for the treatment and prognosis of these lesions.
\end{abstract}

Aims \& objective: Aims of the study were, to study Histopathology of Primary Giant cell-rich lesion of bone, to study the clinico-radiological correlation in these lesions \& to study the diagnostic utility of findings these lesions.

Material \& method: In the present study, we have retrospectively examined 50 cases of primary giant-cell rich lesions of bone using biopsy tissue and large resected tissue material. All patients were diagnosed and treated at our institute from 1/10/2013 to 30/9/2014. Patients' details, Clinical Examination, Histopathological Examination, Radiological details were studied and correlated.

Result \& conclusion: Common lesions under this category were Giant Cell Tumour of Bone (41), Aneurysmal Bone Cyst (04), Giant Cell-Rich Osteosarcoma (02), Giant Cell Reparative Granuloma (02), and Fibrous Dysplasia (01). Detailed Histopathological study and clinic-radiological correlation is very helpful to arrive at precise and accurate diagnosis. This in turn, is very helpful for precise treatment of these patients and to know the prognosis of these patients.

Keywords: giant cell tumor, denosumab, aneurismal bone cyst, clinico-radiologicalhistopathological correlation, bone tumor
Volume 3 Issue I - 2016

\section{Vishal M Modi, Mitul B Modi, Dhaval H Jetly, Shailee P Mehta, Mittal Kundariya, Meghavi Joshi}

Department of Pathology, Gujarat Cancer Research Institute, India

Correspondence: Mitul B. Modi,Address Department of Pathology, Gujarat Cancer Research Institute (GCRI), Tel +919662010331,Email mitul.modi7@gmail.com

Received: September 26, 2016 | Published: October 27,
Abbreviations: GCRG, giant-cell reparative granuloma; GCT, giant-cell tumour of bone; $\mathrm{ABC}$, aneurysmal bone cyst; GCROS, giant-cell rich osteosarcoma; IRB, institutional review board; $\mathrm{H} \& \mathrm{E}$, hematoxylin and eosin

\section{Introduction}

Large group of giant cell rich lesions include: Giant-cell Tumour of bone (GCT), Aneurysmal Bone Cyst (ABC), Giant-cell Reparative Granuloma (GCRG), Giant-cell Rich Osteosarcoma (GCROS) and Fibrous Dysplasia. ${ }^{1-8}$ All giant cell rich lesions have numerous multinucleated osteoclast-like giant cells, but have different clinicoradiological and morphological features. Radiological investigations, like typical anatomic location and age of the patient are important for precise diagnosis. Hence, histopathological study with clinicradiological correlation is mandatory for accurate diagnosis. They are important from the treatment and prognosis aspects, too.

\section{Materials and methods}

A retrospective study, of giant cell rich lesions (50cases) was done at GCRI for the period from October 2013 to September 2014. Each case was investigated according to following details: patients' details, registration no., name, age, sex, clinical examination \& type of specimen. Institutional Review Board (IRB) committee has approved this study for the publication and for further research purposes. On Histopathological Examination, specimens \& biopsies were fixed in $10 \%$ neutral formalin, embedded in paraffin wax, stained with Hematoxylin and eosin (H \& E) \& mounted with DPX, which were examined for the following characteristics: growth pattern, cell size, cell shape, nuclear characteristics, radiological examination, pleomorphism, mitosis, stroma \& necrosis. Radiological findings (X ray, CT scan, MRI, etc.) of all patients are obtained from patient medical records.

\section{Result}

Out of total fifty cases, twenty six cases were female \& twenty four cases were male. Median age of patients was 30years. ${ }^{1}$ Most common presenting complain of the patient is pain and inflammation at local site. On radiological examination (X-Ray of lesion) following features were observed.

i. Giant Cell Tumor: mostly well marginated, purely lytic lesion. 
ii. Aneurysmal Bone Cyst: area of lucency situated eccentrically in medullary cavity.

iii. Giant Cell Reparative Granuloma: mostly radiolucent \& bone, commonly expanded.

iv. Giant Cell Rich Osteosarcoma: ill-defined lytic \& sclerotic lesion.

v. Fibrous Dysplasia: well defined zone of rarefaction \& ground glass app.

vi. Out of total fifty cases, (6cases) $12 \%$ were malignant, and (44cases) $88 \%$ were benign lesions (Figure 1, Figure 2, Figure 3, Figure 4 $\&$ Figure 5).

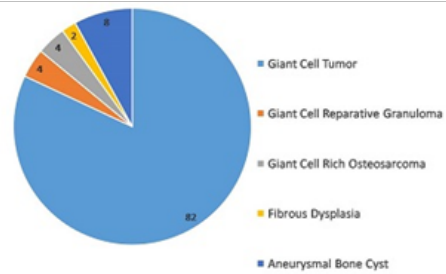

Figure I graphical distribution of giant cell lesions with different proportions of giant cell tumors among them.

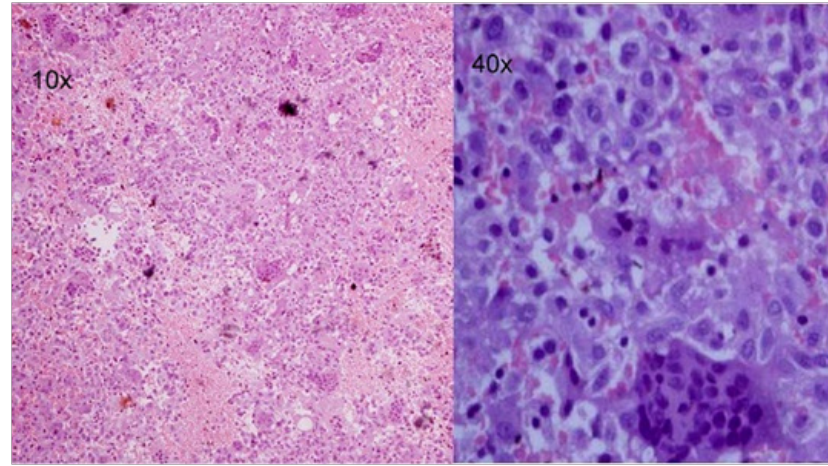

Figure 2 H\&E Stained section show large osteoclast like giant cells and uniform ovoid mononuclear cells (Giant Cell Tumor).

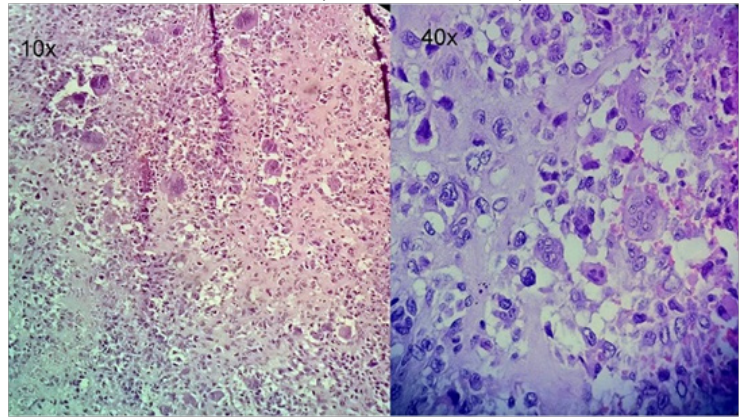

Figure 3 H\&E Stained section show osteoclast like giant cells, mononuclear malignant cells and malignant osteoid (Giant cell rich Osteosarcoma).

On histopathological examination aneurysmal bone cyst showed various cystic spaces separated by blood. Septation is one of the most important aspects of the aneurysmal bone cyst. These septa are composed of osteoclast like giant cell and fibroblast. In selected patients (30) with giant cell rich lesions, when Denosumab was given after the consent of the patients, biopsy of tumor specimens from the same patients showed decreased number of giant cells and tumor cells post treatment with Denosumab. Inoperable tumor becomes operable after that. Pathologist must keep in mind the treatment of the patient while evaluating histopathology of represented material.

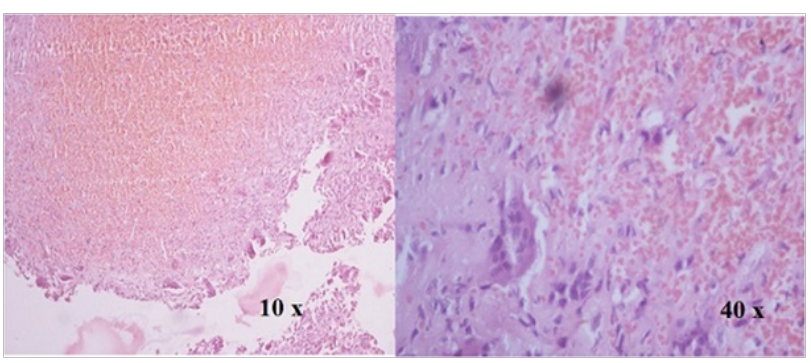

Figure $4 \mathrm{H} \& \mathrm{E}$ Stained section show spaces separated by septa containing blood. Septa compose of osteoclast like giant cell and fibroblast.

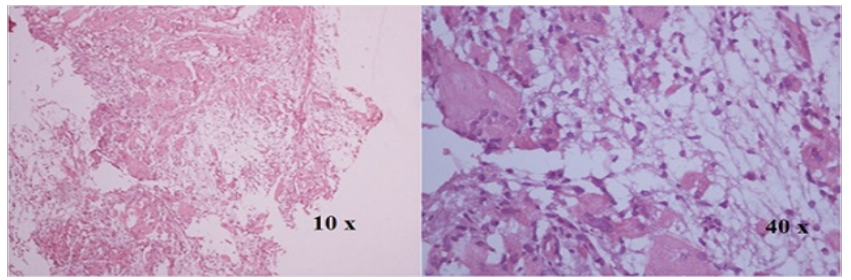

Figure 5 H\&E Stained section show osteoclast like giant cells in cluster and mononuclear cells are loosely arranged and mainly in spindle shape.

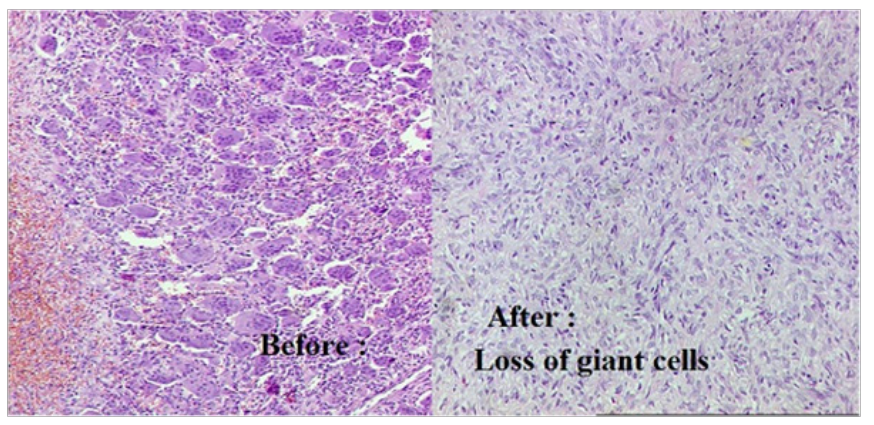

Figure 6 Post treatment changes in morphology, H \& E section showing loss of giant cell in the giant cell rich lesion.

\section{Discussion}

Osteoclast like giant cells may dominate the histologic pattern not only in the giant cell tumor but also a variety of bone lesions namely aneurysmal bone cyst, giant cell-rich osteosarcoma, chondroblastoma, giant cell reparative granuloma and fibrous dysplasia. ${ }^{2-4}$

Most of these occurs in adult life ( $2^{\text {nd }}-3^{\text {rd }}$ decade), except for giant cell tumor and chondroblastoma, Giant cell-rich lesions don't affect the epiphysis on primarily level. In young patient, chondroblastoma and in patient older than 20years, giant cell tumor should be included in differential diagnosis. However, to avoid confusion and to reach to a definitive diagnosis in such cases, it is necessary to take into account histological features, Clinico- radiologic correlation, age of patient and site of lesions.

We studied the mainly the cases of giant cell tumour of bone (41), aneurysmal bone cyst (04), giant cell-rich osteosarcoma (02), giant cell reparative granuloma (02), and fibrous dysplasia (01) at our cancer institute. Detail Histopathological study and clinic-radiological 
correlation is very helpful to reach the precise and accurate diagnosis. This is very helpful for precise treatment of these patients and to know the prognosis of these patients.

Denosumab is very effective in reduction of tumour load. It also causes significant changes in tumour composition in patients with giant cell tumor.

Denosumab is a newer monoclonal antibody which is an inhibitor of Receptor Activator of Nuclear factor Kappa B ligand (RANKL) which causes decrease in number of tumour Giant cells as well as decrease in tumour load (Figure 6). All in all, post Denosumab treatment, tumour size did reduce and in turn inoperable tumour became operable. Pathologist must keep in mind the treatment of the patient while evaluating histopathology of represented material..$^{5-7,9,10}$ Denosumab has proven to be helpful in treatment of aneurysmal bone cyst. $^{9}$

\section{Conclusion}

Detailed histopathological study and clinic-radiological correlation is very helpful to arrive at precise and accurate diagnosis in giant cell rich lesions. Denosumab, a newer monoclonal antibody causes decrease in number of tumor Giant cells as well as decrease in tumor load (GCT). Denosumab is also helpful in treatment of aneurysmal bone cyst. Post Denosumab treatment, tumor size is reduced \& inoperable tumor becomes operable. Pathologist must kept in mind treatment of the patient for proper evaluation of Histopathology of represented material.

\section{Acknowledgements}

We, all authors, would like to thank Dr. R. K. Vyas, Director of Gujarat Cancer \& Research Institute, Ahmedabad for allowing us to publish this article.

\section{Conflict of interest}

The author declares no conflict of interest.

\section{References}

1. Krishnan K Unni, Carrie Y. Tumors of the Bones and Joints. AFIP ATLAS of tumor pathology series $4 ; 2006$.

2. Lang S. Differential Diagnosis of Giant cell rich lesion of bone. Pathologe Suppl. 2008;2:245-249.

3. Rosenberg AE, Nielsen GP. Giant cell containing lesion of bone and their differential diagnosis. Current Diagnostic Pathology. 2001;7(4):235-236.

4. Salzer-Kuntschik M. Differential Diagnosis of Giant cell tumor of bone. Verh Dtsch Ges Pathol. 1998;82:154-159.

5. Xu SF, Adams B, Yu XC, et al. Denosumab and Giant cell tumor of bone-a review and future management considerations. Curr Oncol. 2013;20(5):442-447.

6. Hakozaki M, Tajino T, Yamada H, et al. Radiological and pathological characteristics of giant cell tumor of bone treated with denosumab. Diagn Pathol. 2014;9:111.

7. Branstetter, Nelson SD, Manivel JC, et al. Denosumab induces tumor reduction and bone formation in patients with giant-cell tumor of bone. Clin Cancer Res. 2012;18(16):4415-4424.

8. Thomas, David M, Keith M, et al. Giant cell tumors of bone. Curr opinion oncol. 2009;21(4):338-344.

9. Lange T, Stehling C, Fröhlich B, et al. Denosumab: a potential new and innovative treatment option for aneurysmal bone cysts. Eur Spine J. 2013;22(6):1417-1422.

10. Xu SF, Adams B, Yu XC, et al. Denosumab and giant cell tumour of bone-a review and future management considerations. Curr Oncol. 2013;20(5):e442.

11. Skubitz, Keith M. Giant cell tumor of bone: current treatment options. Curr Treat Options Oncol. 2014;15(3):507-518. 